Editorial

J Gynäkol Endokrinol 2017 · 27:139

https://doi.org/10.1007/s41974-017-0024-6

(c) Springer-Verlag GmbH Austria, ein Teil von Springer Nature 2017

CrossMark

Liebe Leserinnen und Leser!

Mit dieser vierten und letzten Ausgabe unseres Journals in diesem Jahr haben wir die Änderungen und Verbesserungen, angefangen von der Umstrukturierung des Editorial Boards bis hin zum Layout und neuen Cover, vorerst erfolgreich abgeschlossen. Wenn Sie diese Ausgabe in Ihren Händen halten, neigt sich das Jahr bereits wieder dem Ende zu und wir haben für Sie auch zum Jahresausklang interessante Beiträge zusammengestellt.

B.-J. Hackelöer stellt in seiner Arbeit „Bildgebende Methoden in der Mammadiagnostik - welche ist die beste?" diese vor, zeigt die Möglichkeiten der verschiedenen Anwendungen auf und diskutiert die Vor- und Nachteile der verschiedenen Techniken der bildgebenden Mammadiagnostik.

L. Auerbach zeigt in seiner Arbeit über „Endokrine antihormonelle Therapie in der Prämenopause" anhand aktueller Studien und den Therapieleitlinien der internationalen und nationalen senologischen Gesellschaften die heutigen Möglichkeiten der Therapie eines prämenopausalen Mammakarzinoms.

L. A. Dröge und S. Verlohren setzen sich in ihrer Arbeit „Präeklampsie. Aktuelle diagnostische und therapeutische Aspekte" mit dieser sehr häufigen Schwangerschaftserkrankung, die aufgrund einer dysfunktionellen Einheit zwischen Mutter, Fetus und Plazenta zu Hypertonie und Proteinurie führt, intensiv auseinander. Bei diesem Beitrag handelt es sich um eine Zweitpublikation.

M. Feichtinger bringt im „NewsScreen Assistierte Reproduktion" zwei englische Publikationen in Kurzform, nämlich „Mitochondrial DNA quantification as a tool for embryo viability

\section{Franz Fischl}

Wien, Österreich

\section{Editorial}

assessment: retrospective analysis of data from single euploid blastocyst transfers" aus Hum Reprod und „Window of implantation transcriptomic stratification reveals different endometrial subsignatures associated with live birth and biochemical pregnancy“ aus Fertil Steril und diskutiert die Relevanz dieser Arbeiten für die Praxis. P. Frigo bespricht im „News-Screen Menopause“ zwei Originalarbeiten über Zusammenhänge zwischen Alkohol, Menopause und Brustkrebs und setzt sich mit Relevanz in der Praxis auseinander.

P. Stute berichtet in „First to know“ kurz und prägnant über die wesentlichen Neuerungen bzw. interessanten Einzelaspekte im neuen Positionspapier der Nordamerikanischen Menopause Gesellschaft (NAMS) zur HRT, die auch für uns von großem Interesse sein können.

A. Tramontana setzt sich in der „Mädchensprechstunde“ mit "Genetik der In(Sub)fertilität" auseinander, verbunden mit einem Expertengespräch mit Univ.-Doz. Dr. Hans-Christoph Duba, Vorstand des Instituts für medizinische Genetik im Johannes Kepler Universitätsklinikum Linz.

In „Menopause heute und morgen“ wird von A. Tramontana in der Serie „Die Wechseljahre ganz natürlich“ das ABC der Heilkräuter, Nährstoffe und Hormone fortgesetzt.

In „Aktuelles“ zeigen uns V. Bezhenar et al. in Zusammenarbeit mit der Abteilung für allgemeine Gynäkologie und gynäkologische Onkologie der Universitätsklinik für Frauenheilkunde Wien „Ergebnisse von 214 Geburten aus Beckenendlage in einem spezialisierten geburtshilflichen Zentrum in St. Petersburg“. In dieser retrospektiven Analyse von 214 Geburten aus Beckenendlage in den Schwangerschaftswochen 24 bis zum
Termin untersuchen sie das Vorgehen bei BEL-Geburten und deren Outcome in diesem Perinatalzentrum - ein vielleicht interessanter Vergleich zu unserem Vorgehen und Ergebnissen bei BEL-Geburten.

Mitteilungen der IVF-Gesellschaft durch den Präsidenten der Gesellschaft G. Freude, Pressetexte und ein Kongressterminkalender vervollständigen diese Ausgabe des Journals in gewohnter Weise.

Im Namen des Verlages, der Redaktion und in meinem Namen als Herausgeber darf ich Ihnen nicht nur eine spannende und interessante Lektüre, sondern auch erholsame Feiertage und alles Gute zum bevorstehenden Jahreswechsel wünschen.

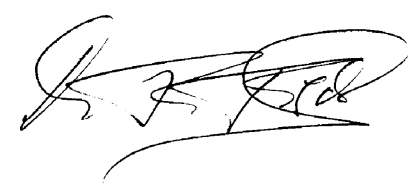

Franz Fischl

Herausgeber

\section{Korrespondenzadresse}

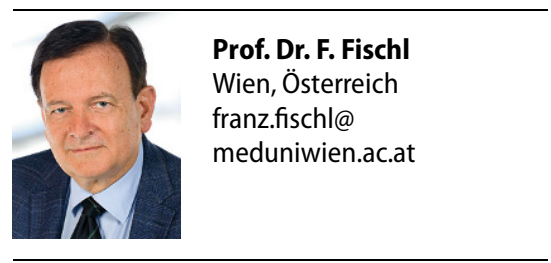

Interessenkonflikt. F. Fischl gibt an, dass kein Interessenkonflikt besteht. 